\title{
Development of a Scale to Evaluate Depressive States among Elderly Patients in General Wards -Verification of the Contents to Improve the Accuracy of the Scale
}

\author{
Tetsuko Takaoka1, Ruriko Kidachi ${ }^{2}$ \\ ${ }^{1}$ Department of Nursing, Faculty of Human Sciences, Hokkaido Bunkyo University, Eniwa, Japan \\ ${ }^{2}$ Graduate School of Health Sciences, Hirosaki University, Hirosaki, Japan \\ Email: tetsumo8@do-bunkyodai.ac.jp
}

How to cite this paper: Takaoka, T. and Kidachi, R. (2021) Development of a Scale to Evaluate Depressive States among Elderly Patients in General Wards-Verification of the Contents to Improve the Accuracy of the Scale. Open Journal of Nursing, 11, 455-465.

https://doi.org/10.4236/ojn.2021.116039

Received: March 26, 2021

Accepted: June 14, 2021

Published: June 17, 2021

Copyright $\odot 2021$ by author(s) and Scientific Research Publishing Inc. This work is licensed under the Creative Commons Attribution International License (CC BY 4.0).

http://creativecommons.org/licenses/by/4.0/

\begin{abstract}
Purpose: This study aims to verify the validity of the contents of the Nurse Administered Depression Scale for Elderly Inpatients16 (NDE16) using the Delphi approach in order to further improve the accuracy of the NDE16, a scale for rating potential depressive states in elderly inpatients through the observations reported by nurses. Methods: Participants were nurses working in general wards for longer than 3 years and who expressed consent to the study participation. Data were collected using the Delphi method (3 times). Responses are scored from 1 to 5 ( 3 - 5 points as positive) using the Likert method. The standard criteria for inclusion in the further evaluation are "mean $\geq 3.0$ ", "standard deviation $<1.0$ ", "median $\geq 3.0$ ", and "IQR $\leq 1.0$ ". Items that meet all the criteria at the third survey are employed as question items in the final questionnaire. Results: The respondents were 139 females, 10 males, and 1 unknown, aged 25 to 65 . The collection rates of the three surveys were $75 \%$ to $82 \%$. Based on the results of the first survey, wordings of 9 questions were modified. Since Question 13 "Queries are not really responded to." did not meet the criteria $(\mathrm{IQR}=2)$ at the third survey, we excluded this question and named the revised scale NDE15. Discussion: The reason why Question 13 did not meet the criteria could be due to the difficulty in distinguishing "Expressing thought suppression" from the state of cognitive decline in dementia. Further studies are needed to determine cutoff points.
\end{abstract}

\section{Keywords}

Depressive States, Elderly Patients, Delphi Approach, General Ward, Non-Self-Rating Scale, Nurses 


\section{Introduction}

\subsection{Background}

Depressive states in elderly people involve thought suppression and restraint in behavior. Further, with many indefinite complaints uttered [1] together, making early detection of a depressive state difficult. The incidence of depressive states in elderly inpatients in general hospital wards in Japan is higher than it is among elderly people living in their private homes [2], making it difficult for elderly inpatients to receive (be administered) regular treatment and appropriate nursing care. However, it is important to identify depressive states among this population. Currently, a self-rating scale is generally used to identify depressive states in elderly people. As Japanese commonly have negative feelings about what should be considered depressive states [3], there are concerns about the psychological burden imposed by having elderly people respond to the depression scale by themselves. This makes it important to be able to make early detection of depressive states without burdening elderly inpatients. For this reason, this study developed a Nurse Administered Depression Scale for Elderly Inpatients 16 (NDE16), which consists of 16 question items in 3 overarching factors and can be scored by nurses through observations [4]. The feature of NDE16 that makes it useful is that it is simple and provides a measure to establish the existence of depressive states without unduly burdening the elderly inpatients being evaluated. The significance of this study is that if the accuracy of NDE16 is improved, the scale could be used and be useful in clinical settings to identify depressive states among elderly inpatients at an early stage of a possibly depressive state, and this could enable the treatment to proceed as optimally scheduled, contributing to improvements in the quality of life (QOL) of the elderly inpatients being evaluated.

\subsection{Purpose}

This study aims to verify the validity of the contents of NDE16 using the Delphi approach in order to further improve the accuracy of the NDE16, a scale for rating potential depressive states in elderly inpatients objectively through the observation of nurses.

\section{Methods}

\subsection{Selection of Study Participants}

We requested cooperation of nursing directors of hospitals with general wards in one city in Japan and included the hospitals that showed consent as participating hospitals. The staff of the participating hospitals involved in this study selected all nurses who met the inclusion criteria for study participation, and distributed a package of documents containing a "Leaflet to explain the purpose and outline of the study", an "Informed consent form", a "Table of demographic questions", a "Research withdrawal form", and an "envelope to use for returning the documents". The nurses who signed and returned the "Informed consent form", and 
"Table of demographic questions" were enrolled in the study. The inclusion criteria were nurses who had experienced working in general wards for 3 years or longer. The NDE16 is a scale for nurses to objectively assess the depressive states in elderly inpatients, and we regarded the nurses who use this scale as the study participants. Benner states that among the characteristic of mid-career nurses is that they possess the skills to distinguish between important and less important situations by understanding situations globally rather than in isolation and disconnected from the whole [5], and that nurses with 3 to 5 years of care experience have this skill [5]. Based on this, we chose to include nurses who have worked in general wards for 3 years or longer. We assumed that the accuracy of the NDE16 would be improved with these inclusion criteria.

\subsection{Data Collection Method}

Data were collected using the Delphi method. In the Delphi method study participants who are experts (here experienced nurses) are sent a questionnaire by post several times to solve problems, and are provided feedback from the previous questionnaire with a new questionnaire for the next round. This allows the researchers to summarize the questionnaire responses into opinions that reach a consensus by distributing and collecting subsequent questionnaires [6]. For this reason, we decided this method to be appropriate to improve the accuracy of the NDE16. The questionnaire included basic demographic question and NDE16 sections. The NDE16 section of the questionnaire measures the levels of depressive states in elderly inpatients using the Likert method ( 3 - 5 points as positive, 1 - 2 points as negative): evaluated as " 5 . Absolutely appropriate", "4. Appropriate", "3. Slightly appropriate", "2. Slightly inappropriate", and "1. Absolutely inappropriate". Further, there is an open-ended part where participants describe their personal opinions and provide feedback. The questionnaires were sent to the study participants by post. The recipients of the questionnaires were requested to provide their responses within one month of the arrival of the questionnaires and return them in the enclosed envelope. In the second and third surveys, we sent the feedback documents and revised NDE16 questionnaires. The participants who received these were to complete their responses within one month of the arrival as with the first survey and return them in the enclosed envelope.

\subsection{Data Analysis}

In the analysis, the responses to the question items were scored from 1 to 5 for each item, and the mean, median, standard deviation and interquartile range (index of variation corresponding to the median: IQR), and the agreement rate of 3 to 5 (regarded as positive items) were calculated. The standard criteria for inclusion in the further evaluation were: "mean $\geq 3.0$ ", "standard deviation < 1.0 ", "median $\geq 3.0$ ", "IQR $\leq 1.0$ ", and "agreement rate $\geq 70 \%$ ". Items that met all the criteria at the third survey were employed as question items in the final questionnaire. The mean values and descriptions in the open-ended feedback 
part were utilized to improve the wordings of the question items.

\subsection{Ethical Considerations}

One feature of the NDE16 is that it can be completed in about 5 minutes and without any physical or psychological invasion of the person evaluated, it is assumed that there is no physical or psychological invasion of the study participants (experts) in this study. To lessen any perceived burden needed to complete the survey, we stated that the participants do not necessarily have to post the questionnaire, and that they may post blank response sheets, as well as that the participants can withdraw by submitting a withdrawal form even after they have expressed consent to participate. However, we stated in the explanatory leaflet that the data before withdrawal will not be destroyed as the data is collected anonymously.

For the concern that study participants who refuse to participate will suffer some disadvantage within their organization, we clearly stated that there would be no disadvantages whether participating or not participating, and that if there are questions from participants or participating hospitals, we are always ready to answer these questions. In addition, as it may be difficult to address complaints to the researchers, such complaints would be passed on to the researchers via the member of the staff in charge of the study at the participating hospitals, and this condition was informed to all persons involved in the research. This study was conducted with approval from the Ethics Committee of the university to which the researchers belong (No. 01012).

\section{Results}

\subsection{Demographics of Participants}

Table 1 shows the demographics of the study participants. Of the 300 nurses who received the questionnaires, 150 nurses expressed consent to participate. All the participants lived in Hokkaido, Japan. The respondents were 139 females (92.7\%), 10 males $(6.7 \%)$, and 1 unknown (0.6\%). The mean age was 40.7 years $(\mathrm{SD}=8.7)$, and the mean length of working experience as a nurse was 15.3 years $(\mathrm{SD}=8.1)$. The mean length of service in a general ward was 10.7 years $(\mathrm{SD}=$ 6.7), and in the wards where the respondents were currently working it was 4.3 years ( $\mathrm{SD}=3.8)$; in the general ward(s) where they had previously been working it was 8.9 years $(\mathrm{SD}=6.6)$. The types of wards where the respondents were currently working were 56 in neurosurgery wards (37.3\%), 24 in orthopedic wards (16.6\%), and 23 in cardiovascular wards (surgery/internal medicine) (15.3\%), 6 in ICU (intensive care unit)/SCU (Stroke Care Unit) (4.0\%), 5 in hematology wards, (3.3\%), in gastroenterology wards (3.3\%), and 31 in other wards (20.7\%).

\subsection{First Survey}

The questions of the first survey are shown in Table 2 "1st survey questions". For the first survey, 123 out of 150 participants responded, and the collection 
Table 1. Demographics of participants Demographics of participants $(n=150)$.

\begin{tabular}{|c|c|c|c|}
\hline Domicile & Hokkaido & 150 & $100 \%$ \\
\hline \multirow{3}{*}{ Gender } & Female & 139 & $92.7 \%$ \\
\hline & Male & 10 & $6.7 \%$ \\
\hline & Unknown & 1 & $0.6 \%$ \\
\hline \multicolumn{2}{|r|}{ Mean age } & \multicolumn{2}{|c|}{$40.7(S D 8.7)$} \\
\hline \multicolumn{2}{|c|}{ Mean length of nursing experience (years) } & \multicolumn{2}{|c|}{$15.3(S D 8.1)$} \\
\hline \multicolumn{2}{|c|}{ Mean length of service in a general ward (years) } & \multicolumn{2}{|c|}{$10.7(S D 6.7)$} \\
\hline \multicolumn{2}{|c|}{ Mean length of service in the ward currently working } & \multicolumn{2}{|c|}{$4.3(S D 3.8)$} \\
\hline \multicolumn{2}{|c|}{ Mean length of service in the wards previously working } & \multicolumn{2}{|c|}{$8.0(S D 6.6)$} \\
\hline \multirow{7}{*}{$\begin{array}{l}\text { Ward where participants } \\
\text { are currently working }\end{array}$} & Neurosurgery & 56 & $37.3 \%$ \\
\hline & Orthopedic & 24 & $16.6 \%$ \\
\hline & Cardiovascular wards (surgery/internal) & 23 & $15.3 \%$ \\
\hline & ICU/SCU & 6 & $4.0 \%$ \\
\hline & Hematology & 5 & $3.3 \%$ \\
\hline & Gastroenterology & 5 & $3.3 \%$ \\
\hline & Other & 31 & $20.7 \%$ \\
\hline
\end{tabular}

Table 2. Survey questions.

\begin{tabular}{|c|c|c|}
\hline & 1st survey questions & 2nd and 3rd survey questions (modified) \\
\hline 1 & $\begin{array}{l}\text { Being short-tempered and/or showing } \\
\text { unstable feeling }\end{array}$ & Emotionally unstable \\
\hline 2 & Unstable in mood & Patients have many complaints about other patients \\
\hline 3 & $\begin{array}{l}\text { I am worried about how to intervene to } \\
\text { solve problems. }\end{array}$ & $\begin{array}{l}\text { Elderly patients have problems that improve only with } \\
\text { difficulty }\end{array}$ \\
\hline 4 & Feeling irritated and/or restless & Patients seem frustrated \\
\hline 5 & Showing feelings of desperation & Patients are disappointed by various things \\
\hline 6 & Complaining of being unable to sleep & Complaining of being unable to sleep \\
\hline 7 & Pessimistic & Pessimistic \\
\hline 8 & Expressionless & Expressionless \\
\hline 9 & Reducing interactions with others & Reducing interactions with others \\
\hline 10 & $\begin{array}{l}\text { There are cases where patient does not } \\
\text { appear to understand explanations. }\end{array}$ & Patients do not accept explanations \\
\hline 11 & Unable to switch moods unassisted & Patients cannot change their mood by themselves \\
\hline 12 & Appears dispirited & Patients are spiritless \\
\hline 13 & Lack of comprehension & $\begin{array}{l}\text { Queries are not really responded to? Patients do not } \\
\text { converse and it does not become a true exchange. }\end{array}$ \\
\hline 14 & $\begin{array}{l}\text { Showing negative attitudes toward } \\
\text { encouragements }\end{array}$ & Showing negative attitudes toward encouragements \\
\hline 15 & Stopped doing what he/she was able to & Stopped doing what he/she was able to \\
\hline 16 & $\begin{array}{l}\text { Convinced of being unable to do } \\
\text { something as wished }\end{array}$ & Convinced of being unable to do something as wished \\
\hline
\end{tabular}


rate was $82.0 \%$. Table 3 shows the survey results. The mean value (5-point scale) was 2.9 to 4.3 and the standard deviation 0.8 to 1.1 . The responses of all 16 questions scored at a median of 3 or higher. There were 10 questions with IQR 1.0 and below: Questions 1, 3, 5, 7 - 9, 11, 13, 14, and 16. The comments in the open-ended part include: “About Question 2, patients express many complaints when nurses visit their room, but they do not inform us by nurse calls", "For Question 3, it asks me about my condition, I do not understand whether Question 4 asks me if I am irritated or the patient is irritated as a symptom of a depressive state. I wonder which is correct", overall suggesting that the wordings are unclear and difficult to understand. Based on the comments above, we reviewed the expressions in all questions, and modified 9, including questions 2, 3, and 4. As Question 1 contains two phrases, "short-tempered" and "unstable feeling", we modified the wording to "emotionally unstable" to avoid confusion.

Question 2 was to confirm that nurses have to respond to many complaints. This is the reason we expressed it as that "Patients have many complaints about other patients" based on the comments in the open-ended part. Question 3 was modified to "Elderly patients have problems that improve only with difficulty", making it clear that the subject of the sentence is the elderly inpatients, based on the comment that the subject is not stated clearly. Question 4 could be misunderstood because it contained two adjectives, "irritated" and "depressed". We modified the expression to "Patients seem frustrated". Question 5 was changed

Table 3. Survey results.

\begin{tabular}{|c|c|c|c|c|c|c|c|c|c|c|c|c|}
\hline \multirow{2}{*}{ Item } & \multicolumn{3}{|c|}{ Mean } & \multicolumn{3}{|c|}{ Standard deviation } & \multicolumn{3}{|c|}{ Median } & \multicolumn{3}{|c|}{ IQR } \\
\hline & 1 st & 2nd & $3 \mathrm{rd}$ & 1 st & 2nd & $3 \mathrm{rd}$ & 1 st & 2nd & $3 \mathrm{rd}$ & 1 st & 2nd & $3 \mathrm{rd}$ \\
\hline 1 & 3.6 & 3.9 & 4.1 & 1.1 & 0.9 & 0.7 & 4.0 & 4.0 & 4.0 & 1.0 & 0.0 & 1.0 \\
\hline 2 & 3.1 & 3.2 & 3.3 & 1.1 & 1.0 & 1.0 & 3.0 & 3.0 & 3.0 & 2.0 & 2.0 & 1.0 \\
\hline 3 & 3.3 & 3.4 & 3.5 & 1.0 & 0.9 & 0.8 & 3.0 & 3.0 & 3.0 & 1.0 & 1.0 & 1.0 \\
\hline 4 & 3.2 & 3.2 & 3.3 & 1.0 & 0.8 & 0.9 & 3.0 & 3.0 & 3.0 & 1.8 & 1.0 & 1.0 \\
\hline 5 & 3.5 & 3.6 & 3.7 & 1.1 & 0.9 & 0.8 & 4.0 & 4.0 & 4.0 & 1.0 & 1.0 & 1.0 \\
\hline 6 & 3.9 & 4.0 & 4.3 & 0.9 & 0.8 & 0.8 & 4.0 & 4.0 & 4.0 & 2.0 & 0.0 & 1.0 \\
\hline 7 & 4.2 & 4.0 & 4.2 & 0.9 & 0.7 & 0.8 & 4.0 & 4.0 & 4.0 & 1.0 & 1.0 & 1.0 \\
\hline 8 & 4.3 & 4.4 & 4.5 & 0.8 & 0.7 & 0.7 & 4.0 & 5.0 & 5.0 & 1.0 & 1.0 & 1.0 \\
\hline 9 & 4.1 & 4.0 & 4.1 & 0.8 & 0.8 & 0.8 & 4.0 & 4.0 & 4.0 & 1.0 & 1.0 & 1.0 \\
\hline 10 & 3.0 & 3.1 & 3.2 & 0.9 & 0.9 & 0.8 & 3.0 & 3.0 & 3.0 & 2.0 & 1.0 & 1.0 \\
\hline 11 & 3.6 & 3.7 & 3.8 & 1.0 & 0.9 & 0.9 & 3.0 & 4.0 & 4.0 & 1.0 & 1.0 & 1.0 \\
\hline 12 & 3.9 & 4.1 & 4.2 & 1.0 & 0.7 & 0.8 & 4.0 & 4.0 & 4.0 & 2.0 & 1.0 & 1.0 \\
\hline 13 & 2.9 & 3.0 & 3.0 & 1.0 & 0.9 & 0.9 & 3.0 & 3.0 & 3.0 & 1.0 & 2.0 & 2.0 \\
\hline 14 & 3.4 & 3.5 & 3.7 & 0.9 & 0.9 & 0.8 & 3.0 & 4.0 & 4.0 & 1.0 & 1.0 & 1.0 \\
\hline 15 & 4.0 & 3.9 & 4.1 & 0.9 & 0.8 & 0.7 & 4.0 & 4.0 & 4.0 & 2.0 & 1.0 & 1.0 \\
\hline 16 & 3.4 & 3.4 & 3.5 & 0.9 & 0.9 & 0.8 & 3.0 & 3.0 & 3.0 & 1.0 & 1.0 & 1.0 \\
\hline
\end{tabular}


to "Patients are disappointed by various things" to simply express the state of "giving themselves up to despair". Formerly we used the word "appear" in Question 10 to emphasize that this scale is rated by others. However, as all questions are evaluations by observation, we changed it to simply expressing this as, " $\mathrm{Pa}$ tients do not accept explanations". Questions 11 and 12 were also simplified to "Patients cannot change their mood by themselves" for Question 11, and "Patients are spiritless" for Question 12. Question 13 was improved to express the phenomenon of a lack of comprehension "Queries are not really responded to? Patients do not converse and it does not become a true exchange."

\subsection{Second Survey}

In the second survey, 114 out of the 150 participants responded, and the collection rate was $76.0 \%$. Table 3 shows the survey results. The mean value was 3.1 to 4.4 points and the standard deviation was 0.7 to 1.0. All 16 questions corresponded to a median of 3 or higher. There were 14 questions with IQR 1.0 and below: Questions 1, 3 to 12, and 14 to 16. The comments in the open-ended part are related to cognitive decline like "depressive states and cognitive decline are very confusing", and opinions that point out the "difficulty in deciding whether the patient states in Questions 2, 9, 11, and 15 are due to mood swings (temporary) rather than 'real' depressive states". However, there were no comments about the wordings being unclear. Although there were statements to the effect that it was difficult to decide whether the patient states are due to cognitive decline or mood, all the responses were higher as was the mean values compared to the first survey, except Questions 2 and 16 which had not changed mean values, and Questions 4, 7, and 9 where the mean values decreased. Based on this, we did not modify the question wordings further. In addition, there were no questions with increased standard deviations compared to the first survey. The standard deviations of Questions 9, 10, 14, and 16 did not change, and the remaining questions had decreased standard deviations. Based on these results, we decided that overall the survey had no unclear expressions.

\subsection{Third Survey}

In the third survey, 113 out of 150 participants responded, and the collection rate was $75.3 \%$. Table 4 shows the response ratios for each of the questions in the third survey. Only Question 8 showed an average response score of 5 . There were 10 questions with response ratio 4: Questions 1, 2, 5, 6, 7, 9, 11, 12, 14, and 15. Five questions scored 3: Questions 3, 4, 10,13, and 16, and no questions were scored at 2 or 1 . The question item that did not reach the consensus rate of $70 \%$ or higher was Question 13, only reached consensus rate 69.9\%. The comment in the open-ended part says, "I work in neurosurgery, and it is difficult to determine the depressive states of elderly patients. Depending on the wards of employment, there may be some bias in making decisions." No additional corrections were made to the question wordings because of the NDE16 features that it 
Table 4. Response ratios for each of the questions in the 3rd survey.

\begin{tabular}{|c|c|c|c|c|c|c|c|}
\hline & Question item & 5 & 4 & 3 & 2 & 1 & $\begin{array}{l}\text { Agreement } \\
\text { rate }\end{array}$ \\
\hline 1 & Emotionally unstable & 27.4 & 54.9 & 14.2 & 3.5 & 0.0 & 96.5 \\
\hline 2 & $\begin{array}{l}\text { Patients have many complaints about other } \\
\text { patients }\end{array}$ & 10.6 & 36.3 & 29.2 & 23.9 & 0.0 & 76.1 \\
\hline 3 & $\begin{array}{l}\text { Elderly patients have problems that improve } \\
\text { only with difficulty }\end{array}$ & 10.7 & 34.8 & 46.4 & 7.1 & 0.9 & 92.0 \\
\hline 4 & Patients seem frustrated & 11.5 & 27.4 & 46.0 & 13.3 & 1.8 & 85.0 \\
\hline 5 & Patients are disappointed by various things & 15.9 & 48.7 & 27.4 & 8.0 & 0.0 & 92.0 \\
\hline 6 & Complaining of being unable to sleep & 42.9 & 44.6 & 8.9 & 3.6 & 0.0 & 96.4 \\
\hline 7 & Pessimistic & 40.2 & 43.8 & 11.6 & 4.5 & 0.0 & 95.5 \\
\hline 8 & Expressionless & 67.3 & 20.4 & 10.6 & 1.8 & 0.0 & 98.2 \\
\hline 9 & Reducing interactions with others & 35.4 & 44.2 & 19.5 & 0.9 & 0.0 & 99.1 \\
\hline 10 & Patients do not accept explanations & 6.2 & 23.9 & 53.1 & 15.0 & 1.8 & 83.2 \\
\hline 11 & $\begin{array}{l}\text { Patients cannot change their mood by } \\
\text { themselves }\end{array}$ & 21.2 & 47.8 & 24.8 & 4.4 & 1.8 & 93.8 \\
\hline 12 & Patients are spiritless & 34.5 & 52.2 & 10.6 & 1.8 & 0.9 & 97.3 \\
\hline & Queries are not really responded to? & & & & & & \\
\hline 13 & $\begin{array}{l}\text { Patients do not converse and it does not } \\
\text { become a true exchange. }\end{array}$ & 6.2 & 19.5 & 44.2 & 29.2 & 0.9 & 69.9 \\
\hline 14 & $\begin{array}{l}\text { Showing negative attitudes toward } \\
\text { encouragements }\end{array}$ & 16.1 & 46.4 & 32.1 & 4.5 & 0.9 & 94.6 \\
\hline 15 & Stopped doing what he/she was able to & 29.2 & 53.1 & 16.8 & 0.9 & 0.0 & 99.1 \\
\hline 16 & $\begin{array}{l}\text { Convinced of being unable to do something } \\
\text { as wished }\end{array}$ & 11.5 & 38.1 & 41.6 & 7.1 & 1.8 & 91.2 \\
\hline & & \multicolumn{6}{|c|}{ Bold: Maximum \% } \\
\hline
\end{tabular}

determines depressive state based on the condition regardless of the illness or disease. As shown in Table 3, the mean values range from 3.0 to 4.5 , and the standard deviations were 0.7 to 1.0. All 16 questions showed a median of 3 or higher. For the IQR, 15 questions except Question 13 showed 1.0 or below. The values for Question 13 were as follows: mean, 3.0: standard deviation, 0.9, median, 3, and IQR, 2. Since this question did not meet the criteria of the IQR, we excluded Question 13 and named the revised scale, now with 15 questions as NDE15.

\section{Discussion}

\subsection{Validity of Study Participants}

The NDE16 is a scale for nurses to decide on the depressive state of elderly inpatients. The questions of the NDE16 were extracted as a result of a qualitative 
analysis of interviews with nurses with more than 3 years of clinical experience. In the present study, the participants are nurses with more than 3 years of nursing experience working in general wards. As described earlier, Benner states that the characteristic of mid-career nurses is that they have skills to distinguish between important and not important situations by understanding a situation globally rather than with an isolated viewpoint of the situation [5], and that nurses with 3 to 5 years of care experience have this skill [5]. Therefore, we deem that the nurses in the present study had sufficient experience to determine depressive states, and are valid as study participants. Further, Fujita et al. stated that if there are about 50 to 60 participants in the final stage of a study, this number is sufficient for a study using the Delphi method, but that there are large number of articles with 11 to 20 participants [7]. In the present study, more than 100 participants remained from the first to the third surveys, and the collection rate at the final stage was $75.3 \%(n=113)$. Therefore, we deem that the number of participants is quantitatively sufficient, and this supports the validity of the participants.

\subsection{Validity of the NDE15}

As shown in Table 3, the mean and median values increased, and the standard deviation and IQR tended to decrease in the third survey compared to the first and second surveys.

This suggests that the consensus rate increased as the survey proceeded to the next round. Since the present study uses questions carefully selected by factor analysis (Table 5) from the previous study [4], the results of the present study may be concluded to have met the criteria for validity in a Delphi method survey. The NDE16 includes three factors resulting from the factor analysis (Table 5): "a state with difficulty in suppressing emotion", "expressing thought suppression", and "expressing a state of lack of control". "A state with difficulty in suppressing emotion" is measured by Questions 1 to 7. "Expressing thought suppression" is measured by Questions 8 to 13 , and "expressing a state of lack of control" is by Questions 14 to 16 . In this study, only Question 13 did not meet all Delphi criteria at the final stage. Question 13 was an item included in the "Expressing thought suppression", a characteristic of depressive states in elderly people, and was a question created by modifying the wording "Lack of comprehension" to express the phenomenon of lack of comprehension. The reason for the dispersion in the responses to question 13 could be due to the difficulty in distinguishing this "Expressing thought suppression" from the state of cognitive decline in dementia. As described above, there are still five questions for measuring "Expressing thought suppression" even after Question 13 is excluded. This supports the practical realizability of the NDE15 measuring the depressive states in elderly patients.

\subsection{Nursing Issues}

In the present study, the number of questions of the NDE was reduced by 1 from 
16 to 15 . This reduction will make it easier for nurses to evaluate depressive state of elderly patients. In addition, since the NDE15 covers the three factors that are considered in the NDE, it is possible to measure the depressive state of the elderly inpatients, and this means that the questions in the scale developed here have been selected with great care. Early detection of a depressive state in elderly inpatients in Japan is important to become able to provide appropriate treatment during the short hospital stays mandated in Japan. In the future, we aim to determine cutoff points and put the scale into practical use.

Table 5. Results of the factor analysis of the depressive state scale for elderly inpatients and cronbach's $\alpha$ coefficients.

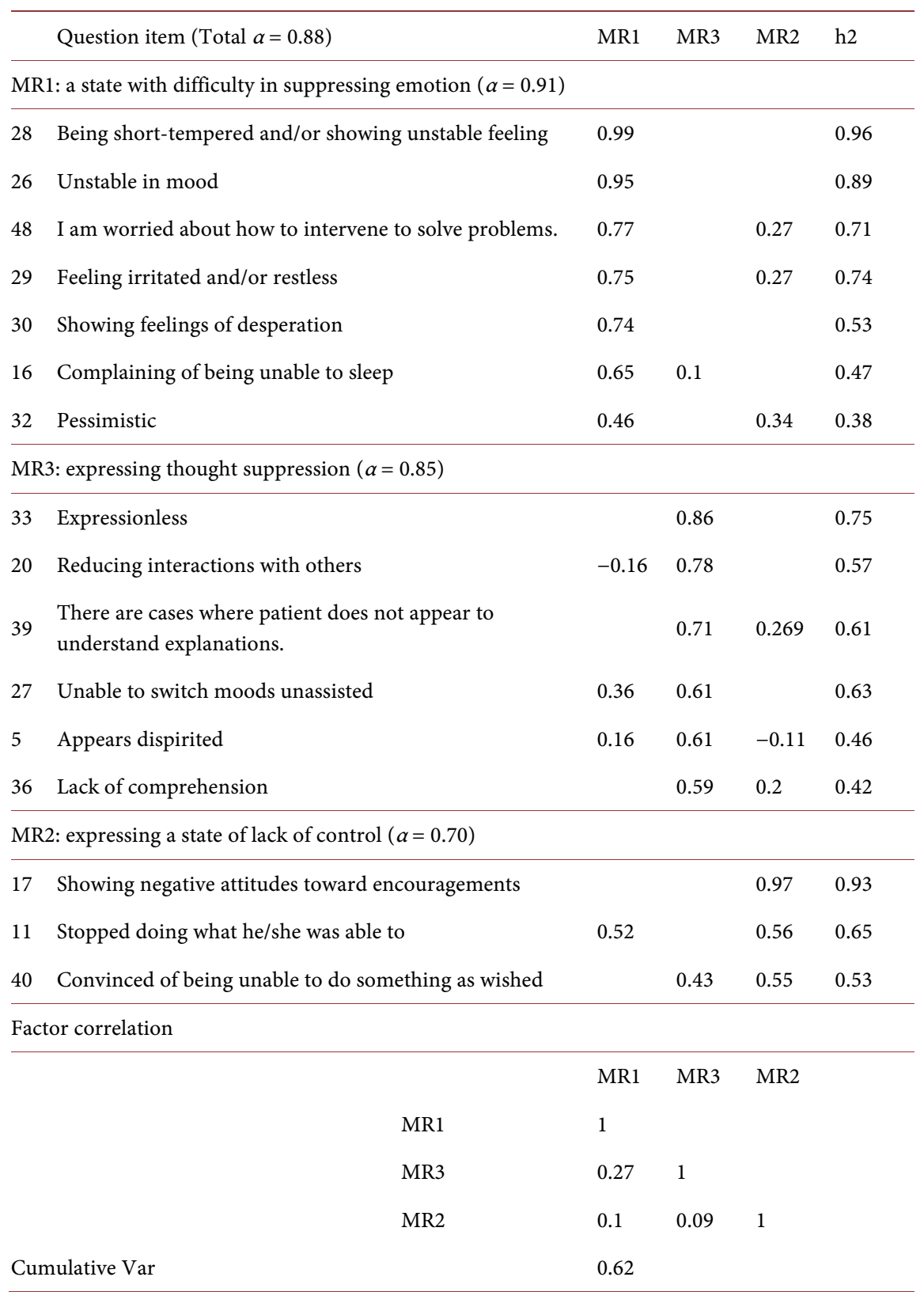

Takaoka, T. \& Kidachi, R. (2017) Development of a scale to evaluate the depressive state among elderly patients in general wards, Open Journal of Nursing, 7(4), 495-512. 


\section{Conclusion}

Based on the results of the third survey, Question 13, which did not meet the Delphi consensus criteria, was excluded and this completed the final formulation of the NDE15. Further studies are needed to determine cutoff points.

\section{Acknowledgements}

We wish to express our gratitude to the participants and staff of all the participating hospitals for their kind cooperation in conducting this research. This study was supported by the Grant-in-Aid for Young Scientists, JSPS KAKENHI (Grant Number 19K19744) for 2019 through 2021. This study is funded by the Ministry of Education, Culture, Sports, Science and Technology (19K197440002) and is properly managed and operated through the Accounting Division of Hokkaido Bunkyo University.

\section{Conflicts of Interest}

The authors declare that the research was conducted in the absence of any commercial or financial relationships that could be construed as a potential conflict of interest.

\section{References}

[1] Igarashi, Y. (2013) What Is a Depressive State? You Are a Good Physician! Identification and Diagnosis of "Depressive States"-Thinking: Oh? Perhaps? Strange? Japan Medical Journal, 26, 1-5. (In Japanese)

[2] Takeda, M. (2011) 6 Depressions: The Japan Geriatrics Society. Textbook of Geriatric Medicine, 3rd Edition, Medical View Co., Ltd., Tokyo, 81-82. (In Japanese)

[3] Nakane, Y., Yoshioka, K. and Nakane, H. (2010) Chapter 3, Japan and Australia Comparative Joint Research on Mental Health. In: Aiming at Mental Barrier-Free Conditions for Depression and Schizophrenia among Japanese, Neisosyobo, Tokyo, 45-83. (In Japanese)

[4] Takaoka, T. and Kidachi, R. (2017) Development of a Scale to Evaluate the Depressive State among Elderly Patients in General Wards. Open Journal of Nursing, 7, 495-512. https://doi.org/10.4236/ojn.2017.74039

[5] Benner, P. (2001) From Novice to Expert: Excellence and Power in Clinical Nursing Practice. Commemorative Edition, Prentice Hall, Hoboken.

[6] Polit, D.F. and Beck, C.T. (2012) Nursing Research: Generating and Assessing Evidence for Nursing Practice. 10th International Edition, Lippincott, New York.

[7] Fujita, Y., Ueki, S. Kitao, M., Maeda, Y. and Fujiwara, C. (2018) Delphi Method Study with Nurses Participants: Survey of the Japanese Literature. Mukogawa Women's University Journal, 3, 35-42. 